\title{
Peningkatan Penggunaan Antibiotik Bijak pada Kelompok Pemberdayaan Wanita di Daerah Perkotaan di Kabupaten Banyumas Melalui Tindakan Intervensi KAP (Knowledge, Attitude, Practice)
}

\author{
Dwi Utami Anjarwati ${ }^{1}$, Rahmawati Wulan Sari², Diyah Woro Dwi Lestari ${ }^{3}$ \\ 1,2,3 Universitas Jenderal Soedirman
}

\begin{tabular}{l} 
Article History \\
\hline Received 21.01 .2019 \\
Received in revised form \\
08.04.2019 \\
Accepted 26.07 .2019 \\
Available online 20.08 .2019
\end{tabular}

\begin{abstract}
INCREASING OF THE USE OF WISE ANTIBIOTIC IN WOMAN'S EMPOWERMENT GROUP IN THE URBAN AREA OF BANYUMAS REGENCY BY PROVIDING INTERVENTION OF KAP (KNOWLEDGE, ATTITUDE, PRACTICE). Unwise use of antibiotic behavior in the community contributes greatly to the increase in the incidence of antibiotic resistance. Antibiotic resistance has become a major health problem throughout the world that must receive attention both in hospitals and in the community. The purpose of this community service is as an effort to increase the use of wise antibiotics in women's empowerment groups in urban areas in Banyumas Regency by intervening Knowledge, Attitude, Practice (KAP). The target audience was an urban community groups in Banyumas regency, namely all members of the Rambutan women's empowerment group located at Jl. Kalijaga, Berkoh, Purwokerto. The activities carried out for KAP intervention were knowledge transfer and educational video included antibiotics, wise use of antibiotics, and the dangers of antibiotic resistance. The results of the KAP intervention were measured by questionnaires containing statements from aspects of Knowledge, attitude, practice before and after KAP intervention activities. Each statement in the questionnaire was assessed with a Likert scale and tested for its validity and reliability. Data were analyzed descriptively, while testing the results of questionnaires I and II were carried out by paired T Tests. Data that can be analyzed are 39 respondents. The results of the questionnaire analysis showed an increase in KAP about antibiotic use before and after KAP interventions in women's empowerment groups in urban areas of Banyumas Regency. The article concluded that an increase in the use of wise antibiotics in women's empowerment groups in urban areas in Banyumas Regency can be achieved by KAP intervention actions.
\end{abstract}

KEYWORDS: Antibiotic Resistance, Attitude, Knowledge, Practice. Attribution 4.0 International License, which permits unrestricted use, distribution, and reproduction in any medium, provided the original work is properly cited. (c) 2019 Dwi Utami Anjarwati, Rahmawati Wulan Sari, Diyah Woro Dwi Lestari.

\footnotetext{
${ }^{1}$ Corresponding author: Departemen Mikrobiologi Fakultas Kedokteran Universitas Jenderal Soedirman Jl. Dr. Gumbreg No I, Medical Street, Mersi, Purwokerto, Indonesia; Email: dwi.anjarwati@ unsoed.ac.id
} 


\section{PENDAHULUAN}

Resistensi antibiotik menjadi masalah kesehatan yang menyita perhatian di seluruh belahan dunia (O'neill, 2014). Akar masalah resistensi antibiotik bukan saja berawal di rumah sakit. Perilaku penggunaan antibiotik secara bebas di masyarakat berkontribusi besar dalam peningkatan kejadian resistensi antibiotik di seluruh dunia. Konsumsi antibiotik tanpa indikasi yang jelas di Indonesia dilaporkan sebanyak 30\% sampai $80 \%$ (Moeloek, 2015a).

Penggunaan antibiotik secara tidak bijak pada mahasiswa kedokteran berhubungan dengan peningkatan karier Escherichia coli penghasil extended spectrum betalactamase (ESBL) telah diteliti oleh tim Fakultas kedokteran Unsoed (Ulla, Afifah, \& Anjarwati, 2018). Penelitian terkait penggunaan antibiotik secara bebas di Surabaya sebelumnya menyimpulkan bahwa sebanyak $17 \%$ antibiotik diperoleh melalui apotek, toko obat, toko obat tradisional tanpa resep dokter. Sementara perilaku penggunaan antibiotik secara tidak bijak dilaporkan pula dalam Riset Kesehatan Dasar (Riskesdas) pada tahun 2013. Prosentase masyarakat yang menyimpan obat di rumahnya adalah $35,2 \%$. Sebanyak $35,7 \%$ dari jumlah tersebut merupakan obat keras dan antibiotik. Prosentase antibiotik yang disimpan sebesar $27,8 \%$ dan dilaporkan antibiotik yang diperoleh tanpa resep dokter adalah sebanyak 86,1\% (Moeloek, 2015a).

Perilaku masyarakat tentang penggunaan antibiotik secara tidak bijak yang berisiko meningkatkan kejadian resistensi antibiotik perlu mendapat perhatian khusus. Penulis sebelumnya melaporkan bahwa intervensi alih pengetahuan dapat berpengaruh pada perubahan persepsi masyarakat daerah pedesaan tentang penggunaan antibiotik secara bijak (Anjarwati, Pribadi, \& Peramiarti, 2017). Sementara di negara lain seperti Arab Saudi dilaporkan bahwa pengetahuan dan pemahaman penggunaan antibiotik bijak masih sangat rendah pada masyarakat usia dewasa (Al-Shibani et al., 2017).

Intervensi knowledge, attitude, practice (KAP) merupakan metode kuantitatif yang diukur dengan kuesioner. Intervensi KAP dapat menggali kekeliruan pemahaman yang berpotensi menjadi hambatan potensial terhadap perubahan perilaku. Kegiatan ini dapat menjadi strategi intervensi yang mencerminkan suatu kondisi lokal, pengaruh faktor budaya serta merencanakan kegiatan sesuai dengan kondisi populasi yang terlibat (USAID, 2011).

Oleh karena itu, pada pengabdian masyarakat saat ini dilaporkan pengaruh intervensi KAP dalam penggunaan antibiotik secara bijak terutama pada masyarakat perkotaan. Perbedaan karakteristik masyarakat perkotaan dan pedesaan mendasari pemilihan khalayak sasaran. Tujuan yang akan dicapai dalam pengabdian masyarakat ini adalah: sebagai upaya peningkatan penggunaan antibiotik bijak pada kelompok pemberdayaan wanita di daerah perkotaan di Kabupaten Banyumas dengan tindakan intervensi KAP.

\section{METODE PELAKSANAAN}

Khalayak sasaran yang dipilih adalah kelompok masyarakat perkotaan di kabupaten Banyumas, yaitu seluruh anggota kelompok pemberdayaan wanita Rambutan yang berlokasi di jl. Kalijaga, Berkoh, Purwokerto dengan jumlah anggota kurang lebih 70 
orang. Kelompok ini dipilih karena merepresentasikan kelompok masyarakat perkotaan. Kelompok pemberdayaan wanita memiliki tugas pokok sebagai seorang ibu yang sangat berkaitan erat dengan urusan logistik termasuk konsumsi antibiotik bagi keluarga.

Tindakan intervensi KAP yang diukur dengan kuesioner berisi pernyataanpernyataan dari aspek Knowledge, attitude, practice. Validitas kuesioner telah diuji dengan uji Pearson product-moment, sementara reliabilitas kuesioner diuji dengan uji cronbach alpha. Kuesioner terdiri dari 21 item pernyataan berisi 7 item tentang knowledge, 7 item tentang attitude, dan 7 item tentang practice. Kuesioner diukur dengan skala likert. Skala likert yang digunakan pada pernyataan positif terdiri dari sangat setuju (SS, skala 5), setuju (S, skala 4), kurang setuju (KS, skala 3), tidak setuju (TS, skala 2) dan sangat tidak setuju (STS, skala 1). Pernyataan negatif memiliki nilai sebaliknya yaitu sangat setuju (SS, skala 1), setuju (S, skala 2), kurang setuju (KS, skala 3), tidak setuju (TS, skala 4) dan sangat tidak setuju (STS, skala 5).

Kegiatan intervensi KAP dilaksanakan dengan alur sebagai berikut:

1. Pengisian kuesioner I untuk mengukur KAP subyek sebelum dilakukan intervensi

\section{Intervensi}

a Knowledge: Alih pengetahuan (ranah afektif) tentang fungsi, jenis antibiotik, bahaya resistensi antibiotik serta kondisi dasar yang memerlukan antibiotik oleh narasumber dari bidang ilmu mikrobiologi. Penguatan pemahaman subyek dilakukan dengan cara diskusi dua arah tentang pengamalan penggunaan antibiotik sehari-hari. Alat peraga yang digunakan adalah power point, vidio dan poster.

b. Attitude: diskusi tentang sikap subyek terhadap penggunaan antibiotik sehari-hari. Alat peraga yang digunakan power point, poster dan brosur.

c. Practice: role play dengan alat peraga skenario kasus tentang penggunaan antibiotik yang tepat baik indikasi, dosis, interval, dan lama pemberian. Subyek dibagi menjadi tiga kelompok untuk bermain peran dengan didampingi fasilitator yang berperan memberi arahan tentang pelaksanaan role play.

3. Kuesioner II untuk mengukur KAP subyek setelah rangkaian kegiatan intervensi KAP.

Data dianalisis secara deskriptif, sementara pengujian hasil kuesioner sebelum dan setelah intervensi dilakukan dengan Uji $\mathrm{T}$ berpasangan. Analisis dilakukan agar penarikan kesimpulan valid.

\section{HASIL DAN PEMBAHASAN}

Responden yang memberi pernyataan setuju diberi tindakan intervensi KAP sebanyak 39 orang. Dari 60 peserta yang hadir, 10 orang tidak mengisi informed consent, 11 data subyek tidak dapat dianalisis karena pengisian kuesioner tidak lengkap atau terdapat jawaban ganda pada lembar kuesioner yang diberikan.

Deskripsi responden berdasarkan usia, pendidikan dan pekerjaan dituangkan dalam Tabel 1. Usia subyek terbanyak kurang dari 40 tahun, pendidikan terakhir didominasai oleh lulusan SLTA, sementara jenis pekerjaan responden terbanyak adalah ibu rumah tangga (IRT). Sebanyak 89,74\% menuliskan jenis antibiotik yang pernah dikonsumsi adalah amoxicillin, sementara sisanya tidak menuliskan nama antibiotik. Responden 
mendapatkan antibiotik dengan cara membeli secara langsung di apotik/toko obat maupun berdasar resep dokter.

Tabel 1. Karakteristik Responden

\begin{tabular}{lll}
\hline Kriteria & Frekuensi & Prosentase (\%) \\
\hline Usia & & \\
$\leq 40$ & 18 & 46 \\
$41-$ & 12 & 31 \\
50 & 7 & 18 \\
$51-$ & 2 & 5 \\
60 & & \\
$>61$ & & \\
Pendidikan & & 18 \\
SD & 7 & 23 \\
SLTP & 9 & 46 \\
SLTA & 18 & 13 \\
S1 & 5 & \\
Pekerjaan & & 85 \\
IRT & 33 & 10 \\
Swasta & 4 & 5 \\
PNS & 2 &
\end{tabular}

Hasil analisis kuesioner I dan kuesioner II menggunakan uji $\mathrm{T}$ berpasangan ditunjukkan dalam gambar 1, 2 dan 3.

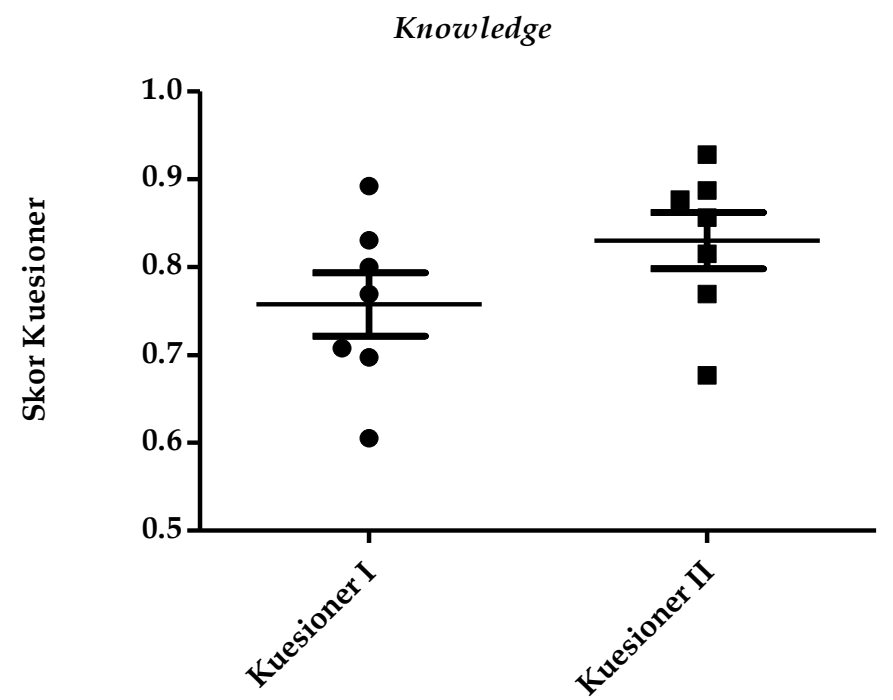

Gambar 1. Grafik Perbandingan Kuesioner I dan Kuesioner II pada Aspek Knowledge 


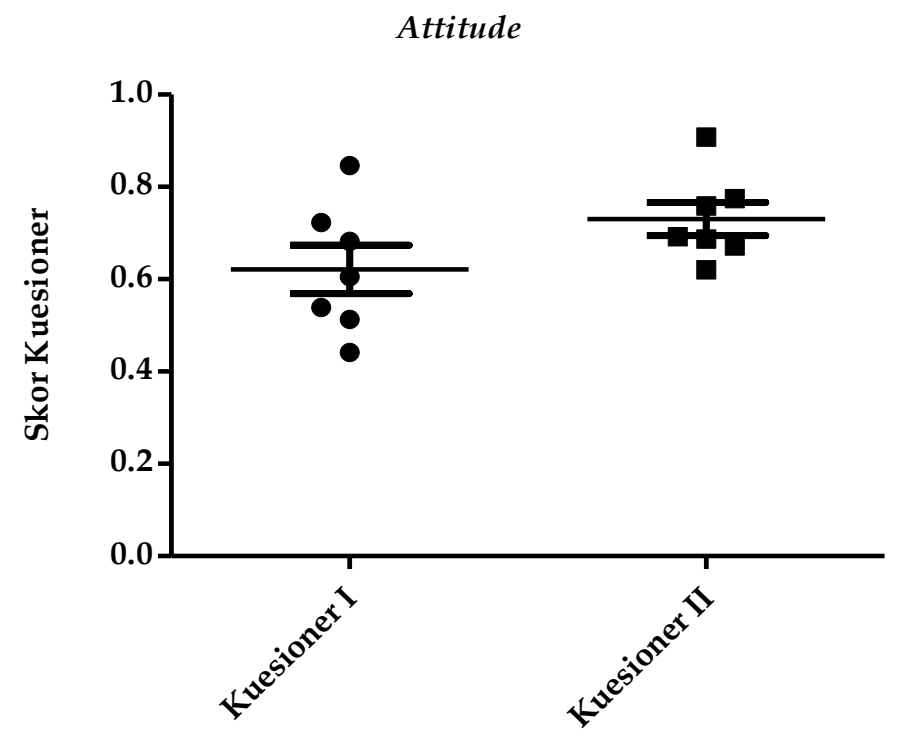

Gambar 2. Grafik Perbandingan Kuesioner I dan Kuesioner II pada Aspek Attitude

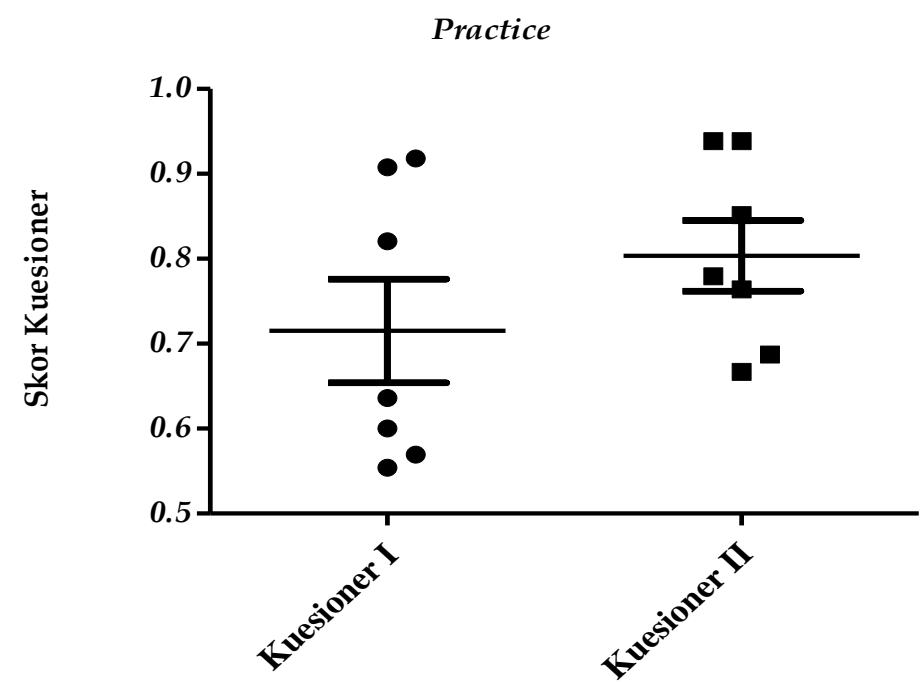

Gambar 3. Grafik Perbandingan Kuesioner I dan Kuesioner II pada Aspek Practice

Hasil skoring kuesioner dan analisis uji T dari kuesioner I dan II ditunjukkan dalam Tabel 2. Ketiga aspek knowledge, attitude dan practice memiliki nilai $\mathrm{p}<0,05$. Hal ini yang menunjukkan bahwa terdapat perbedaan signifikan aspek KAP pada sebelum dan setelah responden diberi intervensi KAP. Artikel terkait sebelumnya memberikan informasi bahwa kegiatan alih pengetahuan dapat meningkatkan persepsi masyarakat di daerah pedesaan di Kabupaten Banyumas (Anjarwati et al., 2017). Perbedaan kedua artikel tersebut adalah dalam hal khalayak sasaran dan intervensi yang diberikan. Artikel terdahulu menguraikan tentang intervensi alih pengetahuan kepada responden kelompok pemberdayaan wanita di daerah pedesaan, sementara pada artikel saat ini intervensi KAP dilakukan terhadap kelompok pemberdayaan wanita di daerah 
perkotaan. Perbedaan karakteristik masyakat pedesaan dan perkotaan mendasari pemilihan khalayak sasaran pada pengambdian masyarakat ini.

Knowledge atau pengetahuan tentang apa yang perlu diubah dan mengapa perlu diubah merupakah faktor vital yang perlu mendapat perhatian untuk terjadinya perubahan. Ketidaktahuan terhadap sesuatu seringkali menjadi masalah utama mengapa seseorang tidak menyadari adanya masalah. Sementara keyakinan dan Attitude/sikap seseorang berpengaruh signifikan terhadap perilakunya. Terjadinya perubahan yang yang diharapkan perlu disertai kemampuan (cara) terbaik untuk melakukan sesuatu (practice) (NHS, 2007).

Tabel 2. Hasil analisis statistik skor pre test dan post test

\begin{tabular}{|c|c|c|c|c|c|c|c|}
\hline \multirow{4}{*}{ No } & \multirow{4}{*}{ Variabel } & \multirow{2}{*}{\multicolumn{2}{|c|}{$\begin{array}{l}\Sigma \\
\text { (Test×Skor)x100\% } \\
\text { skor tertinggi }\end{array}$}} & \multirow{4}{*}{$\mathrm{p}$-value } & \multirow{4}{*}{$\mathrm{R}$} & \multicolumn{2}{|c|}{$95 \% \mathrm{CI}$} \\
\hline & & & & & & \multirow{2}{*}{$\begin{array}{l}\text { Lower } \\
\text { Pre } \\
\end{array}$} & Upper \\
\hline & & Pre & Post & & & & Pre \\
\hline & & $n=39$ & $n=39$ & & & Post & Post \\
\hline A & Knowledge & & & $0,0038^{*}$ & 0,90 & 0,67 & 0,85 \\
\hline 1 & Pernyataan 1 & 0,89 & 0,93 & & & 0,75 & 0,91 \\
\hline 2 & Pernyataan 2 & 0,77 & 0,82 & & & & \\
\hline 3 & Pernyataan 3 & 0,83 & 0,88 & & & & \\
\hline 4 & Pernyataan 4 & 0,80 & 0,89 & & & & \\
\hline 5 & Pernyataan 5 & 0,71 & 0,77 & & & & \\
\hline 6 & Pernyataan 6 & 0,70 & 0,86 & & & & \\
\hline 7 & Pernyataan 7 & 0,61 & 0,68 & & & & \\
\hline B & Attitude & & & $0,0081^{*}$ & 0,87 & 0,49 & 0,75 \\
\hline 8 & Pernyataan 8 & 0,51 & 0,69 & & & 0,64 & 0,82 \\
\hline 9 & Pernyataan 9 & 0,68 & 0,67 & & & & \\
\hline 10 & Pernyataan 10 & 0,44 & 0,62 & & & & \\
\hline 11 & Pernyataan 11 & 0,85 & 0,91 & & & & \\
\hline 12 & Pernyataan 12 & 0,54 & 0,69 & & & & \\
\hline 13 & Pernyataan 13 & 0,72 & 0,77 & & & & \\
\hline 14 & Pernyataan 14 & 0,61 & 0,76 & & & & \\
\hline C & Practise & & & $0,015^{*}$ & 0,94 & 0,57 & 0,86 \\
\hline 15 & Pernyataan 15 & 0,82 & 0,85 & & & 0,70 & 0,91 \\
\hline 16 & Pernyataan 16 & 0,60 & 0,69 & & & & \\
\hline 17 & Pernyataan 17 & 0,55 & 0,76 & & & & \\
\hline 18 & Pernyataan 18 & 0,57 & 0,67 & & & & \\
\hline 19 & Pernyataan 19 & 0,92 & 0,94 & & & & \\
\hline 20 & Pernyataan 20 & 0,64 & 0,78 & & & & \\
\hline 21 & Pernyataan 21 & 0,91 & 0,94 & & & & \\
\hline
\end{tabular}

Ket : ${ }^{*}$ (signifikan) 
Kegiatan intervensi KAP dapat memberikan "pendapat" yang berdasar pada pernyataan "deklaratif". Intervensi KAP dapat menjadi solusi untuk mengatasi kesenjangan antara apa yang dipikirkan, dikatakan dan apa yang telah dilakukan. Pemberian intervensi KAP dapat pula digunakan untuk mengukur suatu kondisi, mengkonfirmasi atau membantah hipotesis, meningkatkan pengetahuan, sikap, dan praktik tema tertentu, mengidentifikasi apa yang diketahui dan dilakukan tentang berbagai topik kesehatan, menetapkan nilai referensi untuk suatu penilaian, dan membantu mengukur efektivitas kemampuan kegiatan pendidikan kesehatan untuk mengubah perilaku terkait kesehatan (USAID, 2011).

Pemberian intervensi KAP dalam konteks pengendalian resisitensi antibiotik merupakan strategi mengendalikan berkembangnya bakteri resisten akibat selective pressure oleh antibiotik. Hal ini dapat tercapai apabila KAP masyarakat dapat berubah dengan cara menggunakan antibiotik secara bijak (Moeloek, 2015b). Hal senada disampaikan oleh peneliti di Kuwait. Pemberian intervensi multifaset diperlukan untuk merasionalisasi penggunaan antibiotik, sehingga dapat mengurangi kesenjangan pengetahuan dan sikap sebagai upaya untuk mencegah pengendalian resistensi antibiotik (Awad \& Aboud, 2015).

Namun demikian, pada penelitian yang dilaporkan oleh Ivanovska dkk pada tahun 2018, menyatakan bahwa untuk terjadinya perubahan signfikan terhadap pengetahuan, sikap dan penggunaan antibiotik yang bijak perlu dilaksanakan intervensi KAP dalam jangka waktu yang cukup lama. Dalam artikel tersebut disimpulkan pula bahwa perlu upaya komprehensif yang melibatkan penyedia layanan kesehatan secara aktif serta pengawasan untuk meningkatkan penggunaan secara bijak (Ivanovska, Verica; Angelovska, Bistra; van Dijk, Liset; Zdravkovska, Milka; Leufkens, Hubert G., \& MantelTeeuwisse, 2018).

\section{SIMPULAN}

Peningkatan penggunaan antibiotik bijak pada kelompok pemberdayaan wanita di daerah perkotaan di Kabupaten Banyumas dapat dicapai dengan pemberian intervensi knowledge, attitude dan Practice.

\section{UCAPAN TERIMA KASIH}

Penulis menyampaikan ucapan terimakasih kepada LPPM Universitas Jenderal Soedirman yang telah memberikan dana BLU untuk pengabdian masyarakat dengan skema Penerapan IPTEKS 2018.

\section{REFERENSI}

Al-Shibani, N., Hamed, A., Labban, N., Al-Kattan, R., Al-Otaibi, H., \& Alfadda, S. (2017). Knowledge, attitude and practice of antibiotic use and misuse among adults in Riyadh, Saudi Arabia. Saudi Medical Journal, 38(10), 1038-1044. doi: 10.15537/smj.2017.10.19887 
Anjarwati, D. U., Pribadi, F. W., \& Peramiarti, I. (2017). Peningkatan penggunaan antibiotik secara bijak melalui intervensi alih pengetahuan untuk merubah persepsi masyarakat di kabupaten Banyumas. Jurnal Pengabdian Pada Masyarakat, 2(2), 93-100.

Awad, A. I., \& Aboud, E. A. (2015). Knowledge, attitude and practice towards antibiotic use among the public in Kuwait. PloS one, 10(2), e0117910. doi: 10.1371/journal.pone.0117910.

Ivanovska, Verica; Angelovska, Bistra; van Dijk, Liset; Zdravkovska, Milka; Leufkens, Hubert G., \& Mantel-Teeuwisse, A. K. (2018). Change in parental knowledge, attitudes and practice of antibiotic use after a national intervention programme. European Journal of Public Health, 28(4), 724-729, doi: 10.1093/eurpub/ckx240.

Moeloek, N. F. (2015a). Menkes canangkan gerakan masyarakat cerdas menggunakan obat, 1-2. Jakarta: Kemenkes RI.

Moeloek, N. F. (2015b). Peraturan Menteri Kesehatan Republik Indonesia Nomor 8 Tahun 2015 tentang Program pengendalian resistensi antibiotik di rumah sakit. Jakarta: Kemenkes RI.

O'neill, J. (2014). Antimicrobial resistance: tackling a crisis for the health and wealth of nations. Review on Antimicrobial Resistance, 20, 1-16.

NHS. (2007). How to change practice. High Holborn: London National Institute for Health and Clinical Excellence. Retrieved from https://www.nice.org.uk

Ulla, I. M., Afifah, \& Anjarwati, D. U. (2018). Hubungan riwayat penggunaan antibiotik dengan karier eschericia coli penghasil extended spectrum beta lactamase (ESBL) pada mahasiswa FK Unsoed angkatan 2014. Purwokerto: Unsoed.

USAID. (2011). The KAP survey model (Knowledge, Attitudes, Practices) caring capacity $\mathcal{E}$ practices. Washington, DC: USAID. Retrieved from https://www.springnutrition.org/publications 